\title{
Brazilian Journal of Geology on its way to full internationalization
}

One of the main objectives of the Brazilian Society of Geology (SBG) is to disseminate and raise the level of Geosciences in Brazil. To achieve these goals, the society uses its journal as its main tool, created in 1945 under the title Boletim da Sociedade Brasileira de Geologia, renamed in 2013 to Brazilian Journal of Geology (BJG) to replace Revista Brasileira de Geociências. In recent years, SBG has made efforts to strengthen and enhance the quality of the journal.

Let us look at the actions and results:

1. Establishment of an electronic management system for manuscript submission;

2. Creation of the online version of the journal, with insertion of the articles on the website of SBG;

3. Update of the 4 quarterly issues per year, in online and printed versions, since the end of 2011 , having published 90 articles in the last 2 years;

4. Hiring of a specialized company to manage article submission and reviews, and to produce BJG professionally, involving formatting, proofreading and English language review;

5. Redefinition of scope, aiming to clarify and orient authors on the journal's field of action;

6. Indication of a new editor-in-chief (Professor Umberto Cordani, USP), associate editor (Professor Claudio Riccomini, USP) and new editorial board, with 15 Brazilian and 15 foreign members, in order to raise the level of articles and promote the internationalization of the journal;

7. Encouraging submissions of papers in English, having produced some issues with articles predominantly in that language; in issue 44, 2014, 41 articles were published, being 28 in English;

8. Reduced time between submission and publication of articles to about six months;

9. The number of downloads of online versions of the articles has increased with time. Currently, the daily average is under 10 , but there are peaks above 30 ;

10. BJG is currently indexed in Scopus and SciELO, and its registration to the Web-of-Science has been requested to Thomson \& Reuters;

11. The review of its classification at Qualis was also requested to CAPES;

12. Over the past three years, according to Scopus, BJG reached 128 citable docs.

These actions have brought results that go beyond those initially planned by the Executive Board of the SBG in conjunction with the Editorial Board of BJG, and has pushed the journal to a level of stability, with high-level content and recognition of the community as the main Brazilian publication in the field of Earth Sciences. At the same time, when BJG completes two years of existence, we are encouraged to face new challenges such as seeing the magazine taking advances in knowledge produced in Brazil and neighboring countries into the world, as it portrays the level of Geosciences in our country. To achieve that, some goals must be pursued, as proposed by those leading BJG:

1. Achievement of financial means to ensure the maintenance of punctuality and increased quality in publications;

2. Improving the content of the articles, written predominantly in English;

3. Publication of articles with appeal and international interest, be it the subject matter (problematic and geological context), or the application of methods and modern techniques;

4. Indexation to on a new international basis, such as the Web-of-Science, and increasing ratings in others such as Qualis, CAPES;

5. Increase of the journal's impact as a result of the publication of articles of high interest and the journal's international recognition. 
It is important to highlight that this new challenge is not only owed to the Executive Board of SBG and Editorial Board of BJG, but to the entire Brazilian Community of Geosciences, which has the potential to have its knowledge internationally disclosed and, therefore, to promote a rich exchange of experiences with colleagues from other parts of the world. Finally, we count on the participation of all, submitting their articles and reviews, in this new phase of BJG.

Moacir J. Buenano Macambira $C E O$ of $S B G$ 